\title{
Progressive drought alters architectural and anatomical traits of rice roots
}

Mohamed Hazman ${ }^{1,2}$ and Kathleen M. Brown ${ }^{1 *}$ (D)

\begin{abstract}
Background: Root architectural and anatomical phenotypes are important for adaptation to drought. Many ricegrowing regions face increasing water scarcity. This study describes drought responses of 11 Egyptian rice cultivars with emphasis on plastic root responses that may enhance drought adaptation.

Results: Eleven Egyptian rice cultivars were phenotyped for root architectural and anatomical traits after 6 weeks growth in soil mesocosms under well-watered conditions. Four of these cultivars were more intensively phenotyped under progressive drought stress in mesocosms, using a system where more moisture was available at depth than near the surface. In response to drought stress, all cultivars significantly reduced nodal root number while increasing large lateral root branching density and total lateral root length in the deepest portions of the mesocosm, where moisture was available. Nodal root cross-sectional area, but not stele area, was reduced by drought stress, especially in the basal segments of the root, and the number of late metaxylem vessels was reduced in only one cultivar. Alterations in deposition of lignin were detected by UV illumination from laser ablation tomography, enhanced by digital staining, and confirmed with standard histochemical methods. In well-watered plants, the sclerenchyma and endodermis were heavily lignified, and lignin was also visible throughout the epidermis and cortex. Under drought stress, very little lignin was detected in the outer cell layers and none in the cortex of nodal roots, but lignin deposition was enhanced in the stele. Root anatomical phenes, including cross-section area and metaxylem vessel number and lignin deposition varied dramatically along large lateral root axes under drought stress, with increasing diameter and less lignification of the stele in successive samples taken from the base to the root apex.

Conclusions: Root architectural and anatomical traits varied significantly among a set of Egyptian cultivars. Most traits were plastic, i.e. changed significantly with drought treatment, and, in many cases, plasticity was cultivar-dependent. These phenotypic alterations may function to enhance water uptake efficiency. Increased large lateral root branching in the deep soil should maintain water acquisition, while water transport during drought should be secured with a more extensively lignified stele.
\end{abstract}

Keywords: Rice roots, Drought, Laser ablation tomography images, Architecture, Anatomy, Lignin

\section{Background}

Drought avoidance is one of the most important strategies for maintaining crop yields in water-limited environments. Drought avoidance is most often attributed to root phenes that support better water capture and transport to the shoot (Clark et al. 2002; Lynch et al., 2014). Investigating the architectural and anatomical phenes that contribute to rooting depth is essential for improving crop performance under drought stress (Lynch 2014). Compared to

\footnotetext{
* Correspondence: kbe@psu.edu

1 Department of Plant Science, The Pennsylvania State University, 102 Tyson

Building, University Park, University Park, PA 16802-4200, USA

Full list of author information is available at the end of the article
}

vegetative growth and yield, root traits have not been popular breeding objectives, partly due to the laborintensive nature of root system phenotyping under agronomically relevant conditions. The recent development of high-throughput phenotyping platforms has increased the potential for associating root phenes with water acquisition from drying soil in cereals, including rice (Henry et al. 2012; Kadam et al. 2017) and maize (Lynch et al., 2014; Lynch 2014; Lynch 2018).

Production of rice consumes large amounts of water, two to three times more than dry-land cereals. Attempts to reduce water usage in rice, a semi-aquatic crop, have been limited by its sensitivity to drought stress 
(Wassmann et al. 2009). Since roots are responsible for water acquisition, root architectural and anatomical traits are key to breeding strategies aimed at drought avoidance. Root traits associated with improved drought avoidance include steeper nodal root angle to increase root depth, and larger diameter roots, which are associated with greater ability to penetrate hard soils to access deep water (Gowda et al. 2011).

Rice possesses a fibrous root system comprised of a mix of embryonic and post-embryonic roots with multiple branching orders (Rebouillat et al. 2009). Post-embryonic roots consist of nodal roots arising from each tiller and numerous lateral roots branching from these axes. There are two types of lateral roots in rice, small lateral roots and large lateral roots. Small lateral roots are shorter, more abundant, ageotropic and do not ramify, while large lateral roots are much longer, less abundant, geotropically positive and highly branched. Root length density in deeper soil layers is highly correlated with soil exploration and water uptake efficiency (Kamoshita et al. 2000; Siopongco et al. 2005). Since rice root architecture is characterized by relatively short nodal roots (shorter than maize or barley), the large lateral roots are likely to contribute substantially to deep soil exploration. Increased lateral root formation under drought stress was suggested as a potentially useful adaptation to drought in lowland rice (Morita et al. 2002; Henry et al. 2012). Several studies have associated improved shoot biomass, water uptake, and photosynthesis under drought with plasticity in lateral root development (Suralta et al. 2010; Kano et al. 2011; Kano-Nakata et al. 2011).

Root anatomical phenes influence radial and axial water transport in roots, which would be expected to influence the efficiency of water uptake and distribution (Lynch et al., 2014). Xylem vessel traits (number, diameter and area) affect axial water conductance while cortical traits and the presence of suberized cell layers may affect radial conductance. Larger xylem vessels and thicker roots are characteristic of upland rice and associated with improved drought tolerance (Gowda et al. 2011).

Like many rice-growing areas, Egypt is faced with increasingly limited irrigation water to support rice production. Egypt is the largest rice-producing country in the West Asia/ North Africa region, producing about 4.8 million tons of paddy rice in 2016 (U.S. Department of Agriculture FAS 2018). Rice production in Egypt has always been constrained by the availability of irrigation water, since the region receives minimal rainfall. Production has declined in recent years and is predicted to decline dramatically this year due to government-imposed $33 \%$ reduction in allotted rice growing area for 2018 (Wally and Beillard 2018). These restrictions are motivated by declining water resources to support this popular but water-intensive crop. Sustainable rice production will require cultivars adapted to water-saving management strategies that do not involve continuous flooding, which is the currently most common practice. We hypothesize that cultivars with the ability to adapt their roots to reduced moisture by maintaining root depth and deep branching will be better suited to progressive drought scenarios. Therefore, we investigated the architectural and anatomical traits of several rice cultivars in well-watered conditions and in response to progressive drought in greenhouse mesocosms.

\section{Material and Methods}

Plant Materials, Growth Conditions and Drought Treatment Eleven publicly available lowland rice cultivars (Oryza sativa) developed by the scientific agricultural community in Egypt were obtained from the U.S. National Plant Germplasm System (https://npgsweb.ars-grin.gov/gringlobal/

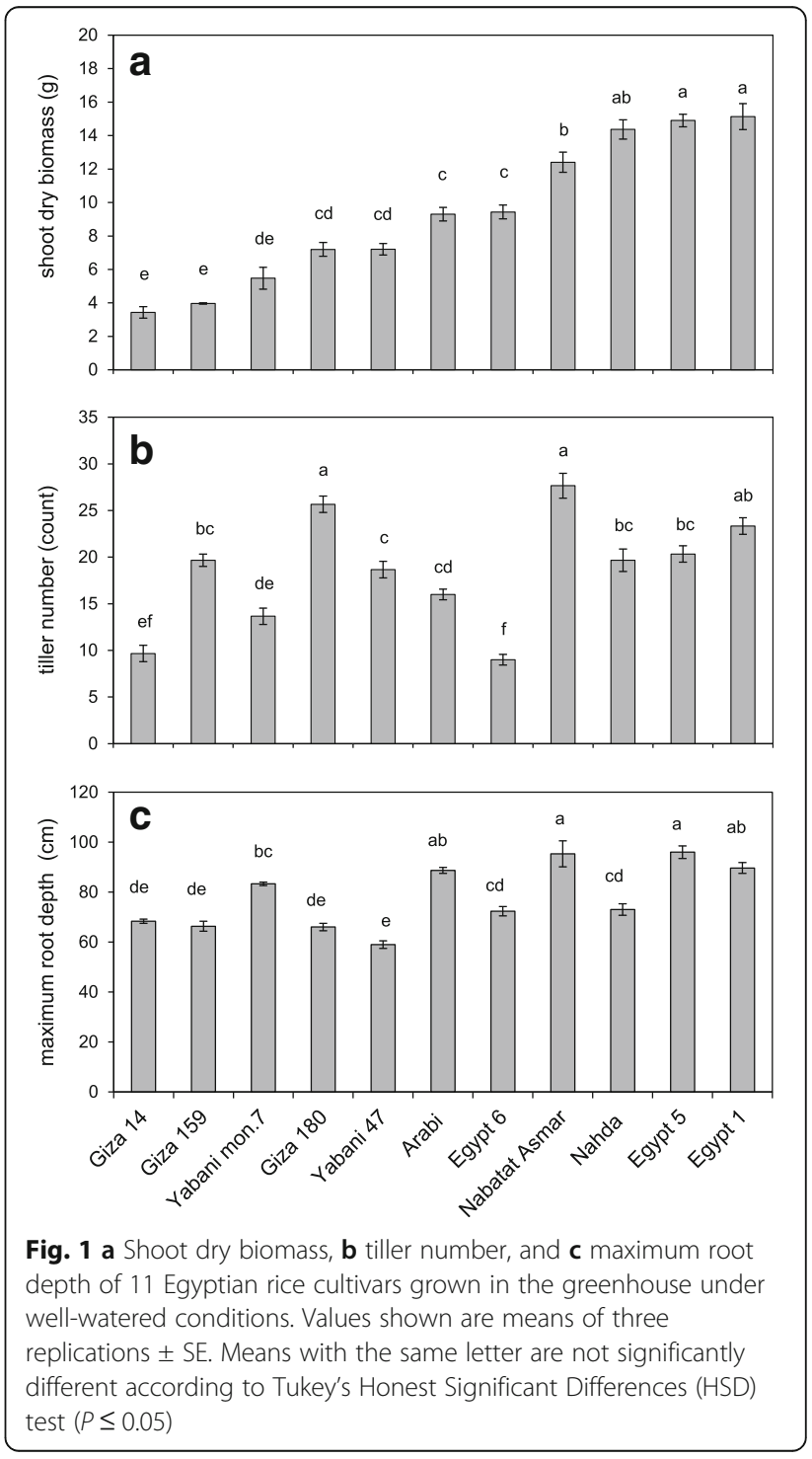


search.aspx). These cultivars varied for days to flowering and represent a range of varietal groups and subpopulations (Additional file 1: Table S1). In the first experiment, all 11 rice cultivars were grown under well-watered conditions to examine root architectural and anatomical traits. In the second experiment, four cultivars with high and comparable vigor in our growth system, Egypt 1, Egypt 5, Nabatat Asmar, and Nahda, were chosen for drought stress (DS) experiments. The experiments were performed in a greenhouse located on the campus of Pennsylvania State University, University Park, PA (40 $\left.48^{\prime} \mathrm{N}, 77^{\circ} 51^{\prime} \mathrm{W}\right)$. The caryopses were dehusked and surface sterilized according to (Hazman et al. 2015) and pre-germinated for 1 week prior to transplanting three healthy seedlings (reduced to one after 3 days) into $1.2 \times 0.15 \mathrm{~m}$ plastic mesocosms. The mesocosms were lined with transparent high-density polyethylene film to facilitate root system excavation and sampling, and filled with a mixture of $40 \%(\mathrm{v} / \mathrm{v})$ medium size commercial grade sand, $45 \%$ vermiculite, $5 \%$ perlite, and $10 \%$ clay topsoil (Hagerstown silt loam, mesic typic Hapludalf) collected from the Russell E. Larson Agricultural Research Center in Rock Spring, Pennsylvania. The mixture was fertilized with $50 \mathrm{~g}$ per mesocosm of Osmocote Plus Fertilizer, which includes micronutrients (Scotts Miracle-Gro Company, Marysville, OH USA). For well-watered treatments, plants were irrigated two times per day with water via drip irrigation $(80-100 \%$ field capacity), and in addition manually received $50 \mathrm{ml}$ per mesocosm per week of Yoshida nutrient solution (Yoshida et al. 1971). Plants were grown to the V8 stage (4 weeks) then harvested. In a separate experiment, four cultivars with similar vigor, Egypt 1, Egypt 5, Nabatat Asmar, and Nahda were grown under well-watered and drought stress conditions. Drought stress treatment was initiated after 2 weeks of growth by allowing the surface to dry gradually for 4 weeks. Soil moisture was monitored digitally with TDR (Time Domain Reflectometer) probes inserted 25 and $100 \mathrm{~cm}$ from the top of the medium of representative mesocosms (Campbell Scientific Inc., Utah, USA). There were no significant differences in volumetric moisture content among cultivars, as measured from the upper or lower sampling positions at the beginning of the drought stress or at the end of the experiment (data not shown). Both well-watered and drought stressed plants were harvested after 6 weeks growth.

\section{Root and Shoot Growth Measurements}

At harvest, tillers were counted and shoots removed for biomass determination. For root sampling, root systems were removed from the mesocosms, facilitated by the presence of a plastic liner. The maximum root depth was recorded in the intact root system, then the root
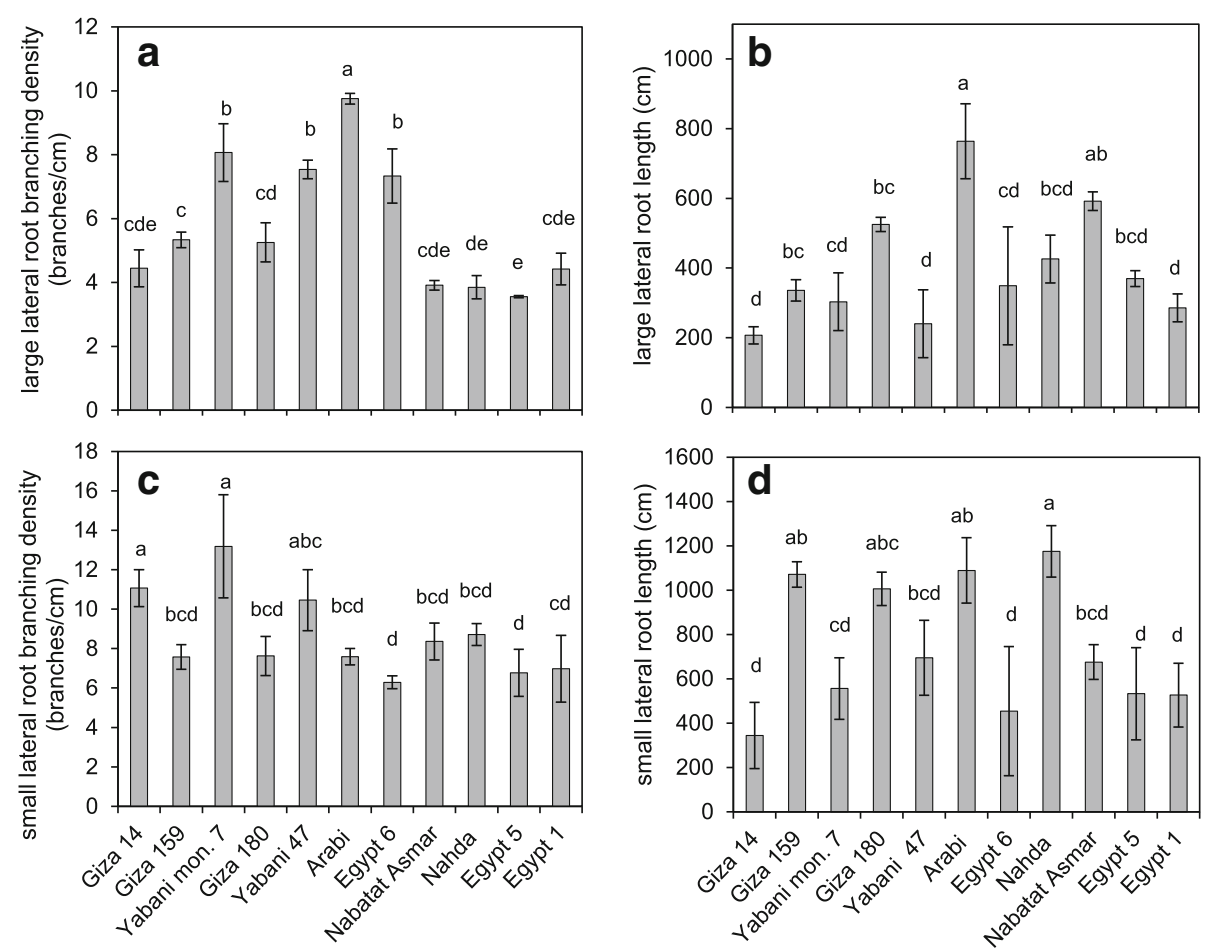

Fig. 2 Genotypic variation among 11 Egyptian rice cultivars in a large lateral root branching density, $\mathbf{b}$ total large lateral root length per nodal root, c small lateral root branching density, and $\mathbf{d}$ total small lateral root length per nodal root in well-watered conditions. Values shown are means of three replications \pm SE. Means with the same letter are not significantly different according to Tukey's Honest Significant Differences (HSD) test $(P \leq 0.05)$ 

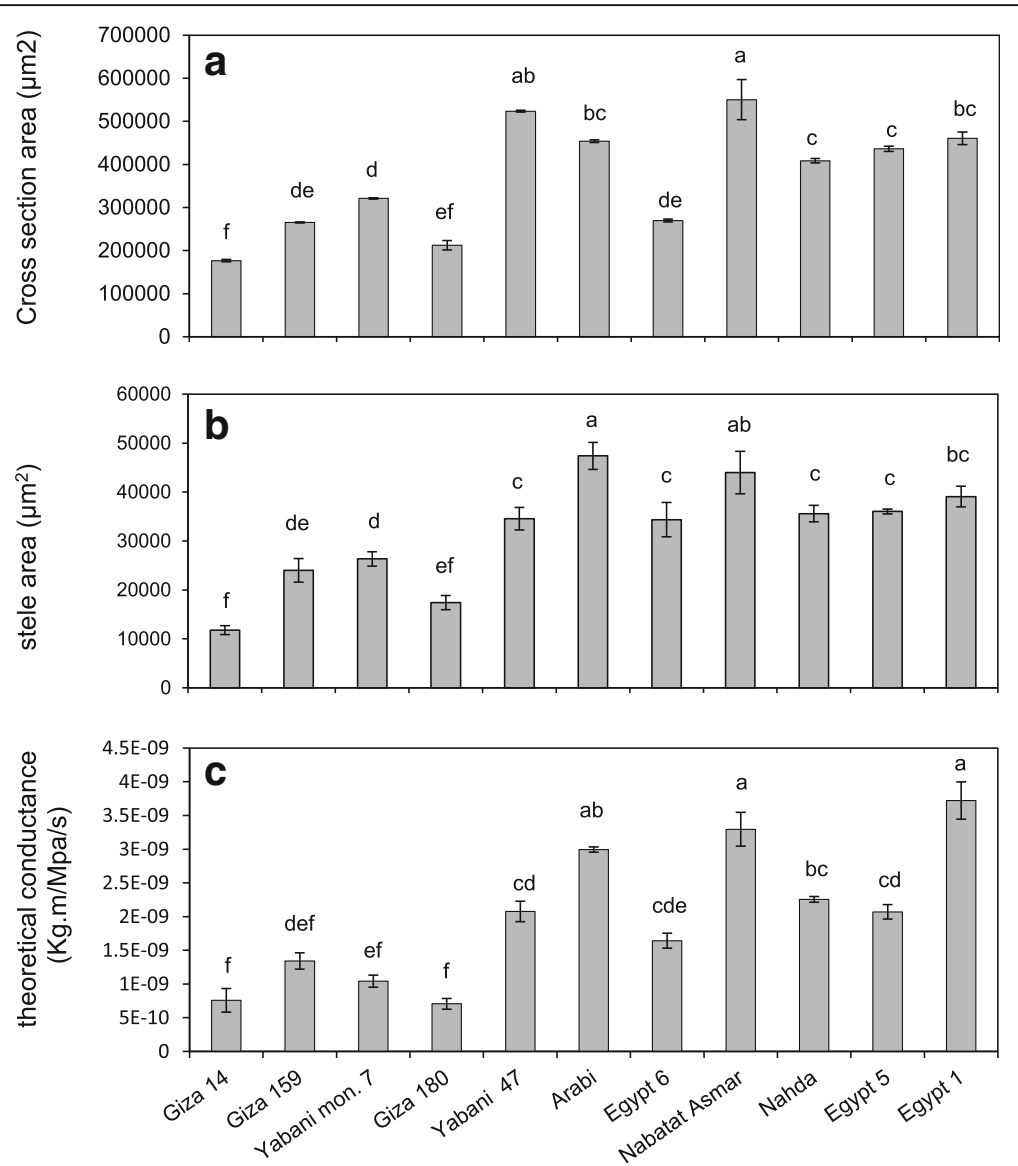

Fig. 3 Nodal root anatomical phenes of 11 Egyptian rice cultivars grown in the greenhouse under well-watered conditions. a cross section area, b stele area, and $\mathbf{c}$ theoretical axial conductance. Values shown are means of three replications \pm SE. Means with the same letter are not significantly different according to Tukey's Honest Significant Differences (HSD) test ( $P \leq 0.05)$

Table 1 Pearson's correlations among root and shoot traits of 11 Egyptian rice cultivars under well-watered conditions

\begin{tabular}{|c|c|c|c|c|c|c|c|c|c|c|c|c|c|}
\hline & $\begin{array}{l}\text { Max. root } \\
\text { depth }\end{array}$ & $\begin{array}{l}\text { Large } \\
\text { LRBD }\end{array}$ & $\begin{array}{l}\text { Small } \\
\text { LRBD }\end{array}$ & $\begin{array}{l}\text { Large } \\
\text { LRL }\end{array}$ & $\begin{array}{l}\text { Small } \\
\text { LRL }\end{array}$ & $\begin{array}{l}\text { Cross section } \\
\text { area }\end{array}$ & Stele area & $\begin{array}{l}\text { Median MV } \\
\text { area }\end{array}$ & $\begin{array}{l}\text { Total MV } \\
\text { area }\end{array}$ & MV No. & $\begin{array}{l}\text { Theor. } \\
\text { cond. }\end{array}$ & $\begin{array}{l}\text { Shoot dry } \\
\text { biomass }\end{array}$ & Tiller No. \\
\hline Max. root depth & 1 & & & & & & & & & & & & \\
\hline Large LRBD & -0.135 & 1 & & & & & & & & & & & \\
\hline Small LRBD & -0.187 & 0.192 & 1 & & & & & & & & & & \\
\hline Large LRL & 0.245 & 0.208 & -0.276 & 1 & & & & & & & & & \\
\hline Small LRL & -0.183 & 0.063 & -0.111 & $0.733^{* *}$ & 1 & & & & & & & & \\
\hline Cross section area & $0.484^{* *}$ & 0.017 & -0.081 & 0.173 & 0.068 & 1 & & & & & & & \\
\hline Stele area & $0.414^{*}$ & -0.271 & $-.538^{* *}$ & 0.275 & 0.205 & $0.563^{* *}$ & 1 & & & & & & \\
\hline Median MV area & 0.224 & -0.008 & 0.303 & 0.145 & 0.259 & 0.342 & 0.267 & 1 & & & & & \\
\hline Total MV area & $0.548^{* *}$ & 0.020 & $-0.364^{*}$ & $0.346^{*}$ & 0.170 & $0.839^{* *}$ & $0.630^{* *}$ & 0.080 & 1 & & & & \\
\hline MV No. & $-0.398^{*}$ & 0.279 & 0.201 & $0.349^{*}$ & $0.504^{* *}$ & -0.199 & -0.003 & 0.237 & -0.280 & 1 & & & \\
\hline Theor. cond. & 0.023 & 0.109 & $0.395^{*}$ & 0.207 & 0.337 & 0.137 & 0.191 & $0.871^{* *}$ & -0.120 & $0.631^{* *}$ & 1 & & \\
\hline Shoot dry biomass & $0.624^{* *}$ & $-0.399^{*}$ & $-0.475^{* *}$ & 0.275 & 0.034 & $0.616^{* *}$ & $0.568^{* *}$ & 0.006 & $0.752^{* *}$ & -0.270 & -0.161 & 1 & \\
\hline Tiller No. & 0.259 & $-0.436^{*}$ & -0.302 & 0.200 & 0.339 & $0.456^{* *}$ & $0.664^{* *}$ & $0.502^{* *}$ & $0.378^{*}$ & -0.016 & $0.372^{*}$ & $0.451^{* *}$ & 1 \\
\hline
\end{tabular}


system was washed with a hose to remove the medium. Nodal root number was recorded, and a representative nodal root was removed and stored in 70\% ethanol for analysis of additional architectural and anatomical traits. The remainder of the root system and the harvested shoots were dried in an $80^{\circ} \mathrm{C}$ oven for $72 \mathrm{~h}$ for dry biomass determinations. Percentage of dry biomass reduction was calculated according to the formula: (WW-DS/WW) $\times 100$, where $\mathrm{WW}=$ well-watered and DS $=$ drought stress .

\section{Root Architecture Measurements}

Total length and branching density of large lateral roots (LLR) and small lateral roots (SLR) on the preserved nodal root sample were measured using WinRhizo (Regent Instruments, Quebec, Canada). The nodal root was divided into several lengths and each length was scanned individually using a flatbed scanner at a resolution of 600 dpi (HP ScanJet, Hewlett Packard, USA). WinRhizo was used to quantify lengths of small and large lateral roots according to the following diameter classes: less than $0.25 \mathrm{~mm}$ SLR, 0.25 to $0.60 \mathrm{~mm}$ for LLR, and larger than $0.60 \mathrm{~mm}$ for nodal roots. SLR were distinguished from LLR based on small diameter and lack of secondary branching. Branching density was calculated by number of tips relative to the length of the nodal root. These measurements were calculated separately

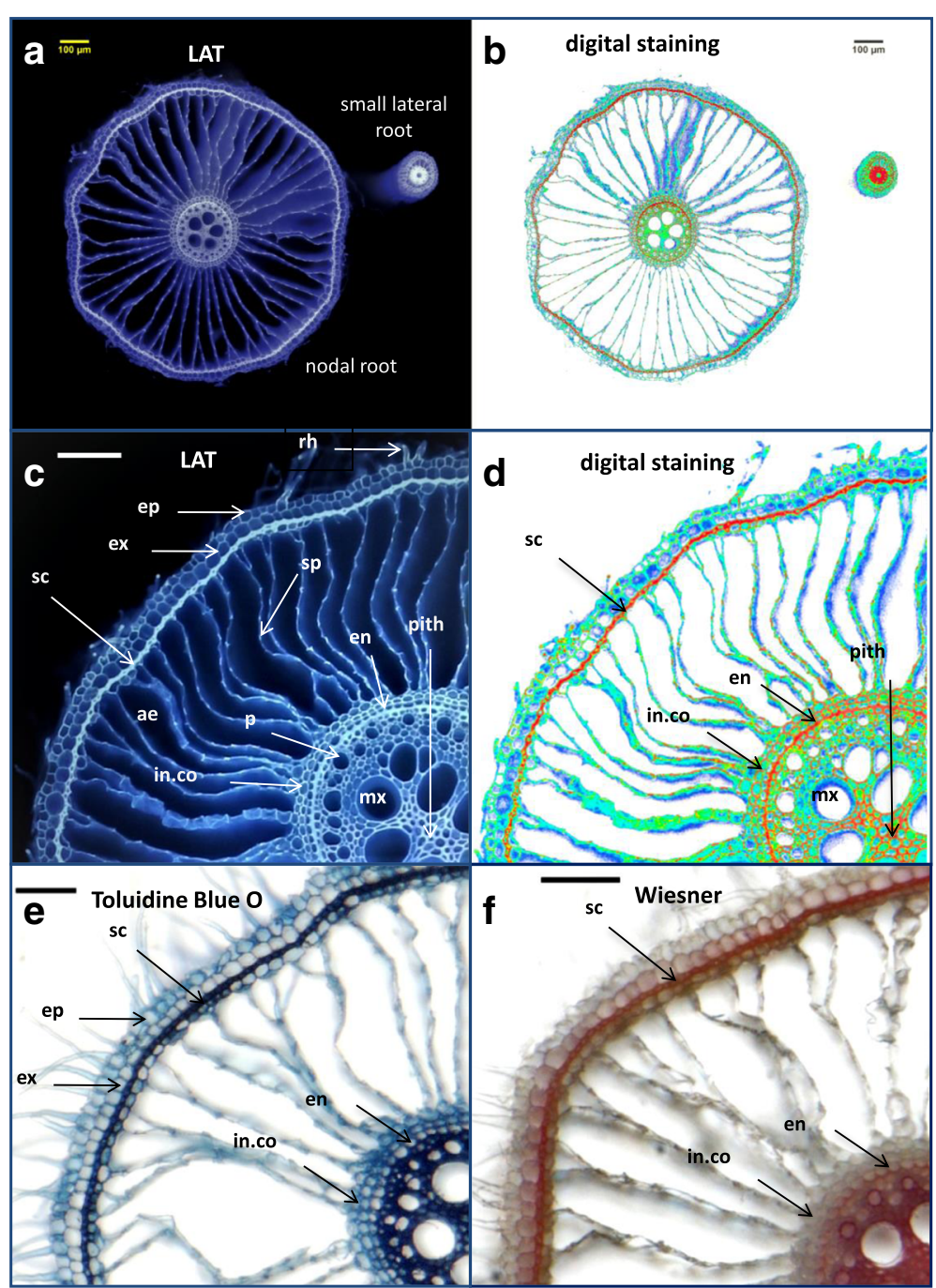

Fig. 4 Comparison of Laser Ablation Tomography (LAT) images plus digital processing with standard histological methods for lignin assessment. Nodal root samples were collected from 4-week-old well-watered Arabi. a LAT image showing a nodal root and a small lateral root; $\mathbf{b}$ the same image digitally "stained"; c enlarged view of a nodal root cross section showing detailed anatomical structures including root hairs (rh), epidermis (ep), exodermis (ex), sclerenchyma (sc), aerenchyma (ae), septa (sp), inner cortical cells (in.co), endodermis (en), phloem (p), metaxylem vessel $(\mathrm{mx})$, and pith; $\mathbf{d}$ digital staining of image "c $\mathrm{c}$ " showing lignin deposition in cell walls of sc, in.co, en and pith. e Toluidine Blue $\mathrm{O}$ staining of hand cross sections of fresh nodal roots showing lignin deposition (blue color) in cells of sc, in co, and en, and $\mathbf{f}$ Wiesner or phloroglucinol-HCl staining showing lignin deposition (reddish-brown color) in sc and en. Horizontal scale bars represent $100 \mu \mathrm{m}$ 
for the apical $20 \mathrm{~cm}$ and for the remaining basal portion of the nodal root.

\section{Measurements of Root Anatomical Phenes}

Dissected rice root segments were imaged using laser ablation tomography (LAT). Preserved root segments from nodal roots were collected at $20 \mathrm{~cm}$ from root base and $10 \mathrm{~cm}$ from root apex and dried with an automated critical point dryer (CPD, Leica EM CPD 300, Leica Microsystem, Vienna, Austria) according to the manufacturer protocol. For LLR anatomy, several LLR of one rice cultivar (Egypt 1) were gently dissected from the nodal root axis and divided with a razor blade into three parts for well-watered plants and five parts for drought-stressed plants and dried using CPD as previously described. Segments of dried nodal and LLR roots were ablated by a laser beam (Avia 7000, $355 \mathrm{~nm}$ pulsed laser) to vaporize the root at the camera focal plane ahead of an imaging stage, then cross-section images were taken using a Canon T3i camera with a $5 x$ micro lens (MP-E $65 \mathrm{~mm}$ ) on the laser-illuminated surface (Chimungu et al. 2015). The resulting images were analyzed by the software MIPAR (Sosa et al. 2014) to obtain areas of the cross-section, stele, and metaxylem vessels. The theoretical axial water conductance of nodal roots was calculated according to Tyree and Ewers (Tyree and Ewers 2018). Picasa software was used to convert the semi-monochromatic high-quality LAT images into complementary diadic colored images with a bright white background using the following recipe: a) Heat map the laser image to $0 \%$ hue and nearly $50 \%$ fade, b) invert the colors, c) cross process, then finally $\mathrm{d}$ ) Orton-ish by $0 \%$ bloom, almost $50 \%$ brightness and $0 \%$ fade. This enabled us to qualitatively distinguish the secondary cell wall elements, and is hereafter referred to as "digital staining".

\section{Histochemical Staining of Secondary Cell Wall Elements}

For histochemistry, ethanol-preserved nodal root segments of one representative cultivar (Egypt 5) were washed gently with deionized water and hand sectioned using a razor blade. Thin sections were stained with three different lignin dyes: $0.02 \%$ toluidine blue, $3 \%$ phloroglucinol-HCL
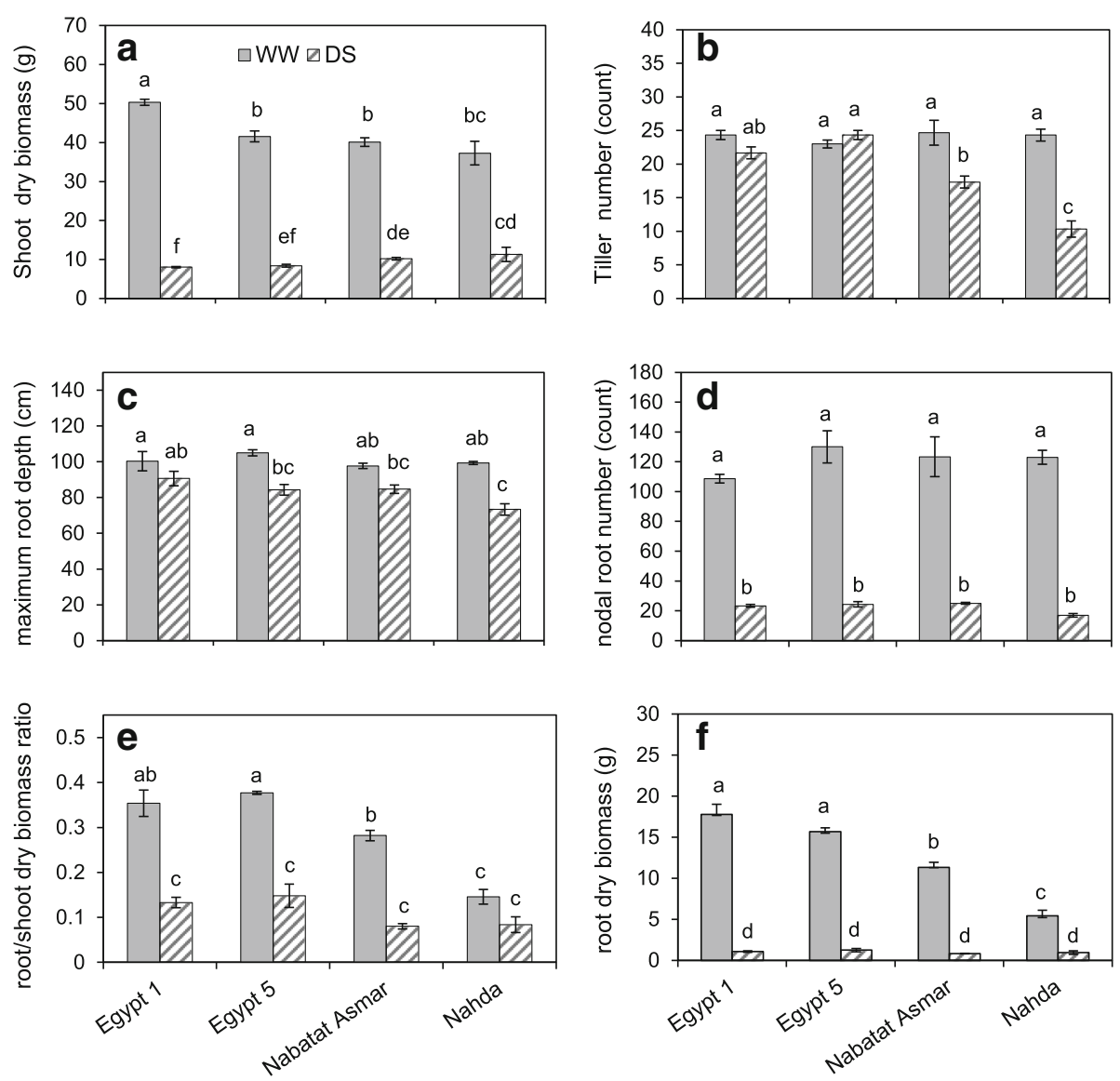

Fig. 5 Effects of drought stress on a shoot dry biomass, $\mathbf{b}$ tiller number, $\mathbf{c}$ maximum root depth, $\mathbf{d}$ nodal root number, e root to shoot ratio, and f root dry biomass of cultivars Egypt 1, Egypt 5, Nabatat Asmar and Nahda. Values shown are means of three replications \pm SE. Means with the same letter are not significantly different according to Tukey's Honest Significant Differences (HSD) test $(P \leq 0.05)$ 
(Weisner staining) and $0.5 \%$ potassium permanganate (Mäule staining) (Sigma-Aldrich, USA). Images of the root sections were acquired with a Nikon SMZ 1500 stereoscope (Nikon, Japan) with 50× and 100× magnification (Pradhan Mitra and Loqué 2014).

\section{Experimental Design and Statistical Analysis}

A randomized complete block design was with at least three independent biological replications. SPSS (IBM Statistics, USA) software was used for statistical tests including mean separations by Tukey's Honestly Significant Difference (HSD) test, with a significance level of $P \leq 0.05$, Pearson correlation coefficient, and ANOVA analysis.

\section{Results}

Root Morphology and Anatomy of 11 Egyptian Cultivars Under Well-watered Conditions

We investigated root architectural and anatomical phenes of 11 cultivars of Egyptian paddy rice grown under wellwatered, aerobic conditions (Additional file 1: Table S1).
There was significant genetic variation in shoot dry biomass, tiller number and maximum root depth of 4-week-old plants (Fig. 1). Both root architectural (Fig. 2) and anatomical (Fig. 3) features showed significant genetic variation. Nahda, Egypt 1 and Egypt 5 produced the greatest shoot dry biomass. Tiller number was weakly correlated with shoot dry biomass and not correlated with maximum root depth (Fig. 1a, c and Table 1). Egypt 5 and Nabatat Asmar had the deepest roots while Yabani 47 had the shortest maximum root depth (Fig. 1c).

Root architecture phenes varied significantly among the rice cultivars (Fig. 2). Arabi had the greatest large lateral root branching density and length. Large and small lateral root branching densities were negatively correlated with shoot dry biomass and large lateral root branching density was negatively correlated with tiller number (Table 1). Small and large lateral root length were highly correlated with each other but were not correlated with lateral root branching density or with shoot biomass (Table 1).

Table 2 Analysis of variance for effects of cultivar and drought treatment on shoot and root traits

\begin{tabular}{|c|c|c|c|}
\hline & Cultivar & Treatment & Cultivar $\times$ Treatment \\
\hline \multicolumn{4}{|l|}{ Growth traits } \\
\hline Shoot dry biomass & 0.99 & $265.02^{* *}$ & $23.35^{* *}$ \\
\hline Tiller number & $15.35^{* *}$ & $60.84^{* *}$ & $20.56^{* *}$ \\
\hline Root dry biomass & $44.80^{* *}$ & $770.00^{* *}$ & $41.40^{* *}$ \\
\hline Root/shoot dry biomass ratio & $29.51^{* *}$ & $209.95^{* *}$ & $10.11^{* *}$ \\
\hline \multicolumn{4}{|l|}{ Root architectural traits } \\
\hline Maximum root depth & 1.16 & $474.88^{* *}$ & 1.14 \\
\hline Nodal root number & $3.69^{*}$ & $63.78^{* *}$ & 2.89 \\
\hline Basal large lateral root branching density & 0.20 & $12.68^{* *}$ & 0.46 \\
\hline Basal small lateral root branching density & $15^{* *}$ & $10.11^{* *}$ & $18.38^{* *}$ \\
\hline Apical large lateral root branching density & 2.66 & $201.42^{* *}$ & $3.74^{*}$ \\
\hline Apical small lateral root branching density & $6.59^{* *}$ & 3.053 & $6.138^{* *}$ \\
\hline Apical large lateral root length & 1.78 & $40.28^{* *}$ & 1.22 \\
\hline Apical small lateral root length & $11.76^{* *}$ & $74.06^{* *}$ & $12.05^{* *}$ \\
\hline \multicolumn{4}{|l|}{ Root anatomical traits } \\
\hline Basal cross section area & $10.02^{* *}$ & $83.38^{* *}$ & $5.84^{* *}$ \\
\hline Basal stele area & 2.31 & 0.16 & $6.28^{* *}$ \\
\hline Ratio of basal cross-section to stele areas & $12.46^{* *}$ & $491.60^{* *}$ & $10.85^{* *}$ \\
\hline Basal median metaxylem vessel area & $4.38^{*}$ & 0.29 & 1.33 \\
\hline Basal metaxylem vessel number & $5.83^{* *}$ & $12.50^{* *}$ & $16.50^{* *}$ \\
\hline Apical cross section area & $10.02^{* *}$ & $83.38^{* *}$ & $5.84^{* *}$ \\
\hline Apical stele area & 3.09 & 8.08 & 0.97 \\
\hline Ratio of apical cross section to stele area & $21.47^{* *}$ & $322.40^{* *}$ & $10.92^{* *}$ \\
\hline Apical median metaxylem vessel area & 1.88 & $5.67^{*}$ & 0.10 \\
\hline Apical metaxylem vessel number & $5.86^{* *}$ & $7.00^{*}$ & $3.57^{*}$ \\
\hline
\end{tabular}

Values shown are $F$ values, and $P$ values are indicated by * $p^{<} 0.05$ and ${ }^{* *} p^{<} 0.01$ 
Root anatomy also varied among cultivars (Fig. 3, Additional file 2: Figure S1). Nodal root cross-sectional area and stele area were positively correlated with shoot dry biomass, tiller number, maximum root depth, and each other (Table 1). Nodal root stele area was negatively correlated with small lateral root branching density and positively correlated with maximum root depth. While median metaxylem vessel area was positively correlated with tiller number, it was not correlated with shoot biomass or metaxylem vessel number. Theoretical axial water conductance, calculated from vessel size and number, was positively correlated with tiller number but not shoot biomass (Table 1).

In order to take the advantage of the variation in auto-fluorescence created by UV-laser beam excitation for lignin visualization, we developed simple approach to convert high quality laser ablation tomography (LAT) images of rice roots (Fig. 4a) into multichromatic images reflecting pixel intensities. These digitally stained images permit high-resolution assessment of tissue-level distribution of lignin in the sclerenchyma, endodermis and stele tissues (Fig. 4a-d). Comparison of these digitally stained images with conventional histochemical staining of lignin using toluidine blue $\mathrm{O}$ and Wiesner (phloroglucinol-HCl) (Fig. 4e-f) demonstrates the coincident indications of lignification. To show that this method is useful for other species, lignin was also digitally visualized in sweet corn primary roots (Additional file 3: Figure S2), where lignin deposition around outer cortical cells and stele cells was clearly visualized using digital staining of a high-quality LAT image.

\section{Drought Responses of Four Egyptian Cultivars: Shoot Growth and Root Architecture}

Four cultivars with the greatest shoot dry biomass without drought (Egypt 1, Egypt 5, Nabatat Asmar and Nahda, Fig. 1) were selected for investigation of the effect of drought on rice root architecture and anatomy. Drought stress was imposed by stopping irrigation so that the upper part of the growth medium became gradually dry while the deep medium retained some moisture. Time domain reflectometry (TDR) probes showed that the volumetric water content $\left(\theta_{v}\right)$ of droughted mesocosms was less than that of well-watered mesocosms, and drier at the top than at the bottom (Additional file 4: Figure S3). Drought stress significantly reduced shoot and root dry biomass and tiller number (Fig. 5, Table 2). Shoot biomass reduction ranged from $70 \%$ in Nahda to $84 \%$ in Egypt 1, and root biomass reduction ranged from $82.65 \%$ in Nahda to $92.81 \%$ in Nabatat Asmar (Fig. 5). Tiller number was significantly reduced in Nahda (58\%) and Nabatat Asmar (30\%).

Maximum root depth did not vary among cultivars in well-watered plants but declined with drought by $20 \%$ to 26\% (Fig. 5, Table 2). Drought stress reduced nodal root number to a much greater extent, averaging more than $80 \%$ reduction in all cultivars (Fig. 5). Drought stress significantly reduced root to shoot ratio in all cultivars except Nahda.

Lateral root branching varied along nodal root axes, with greater branching in the deeper segments of the roots under drought (Fig. 6). We therefore separately evaluated

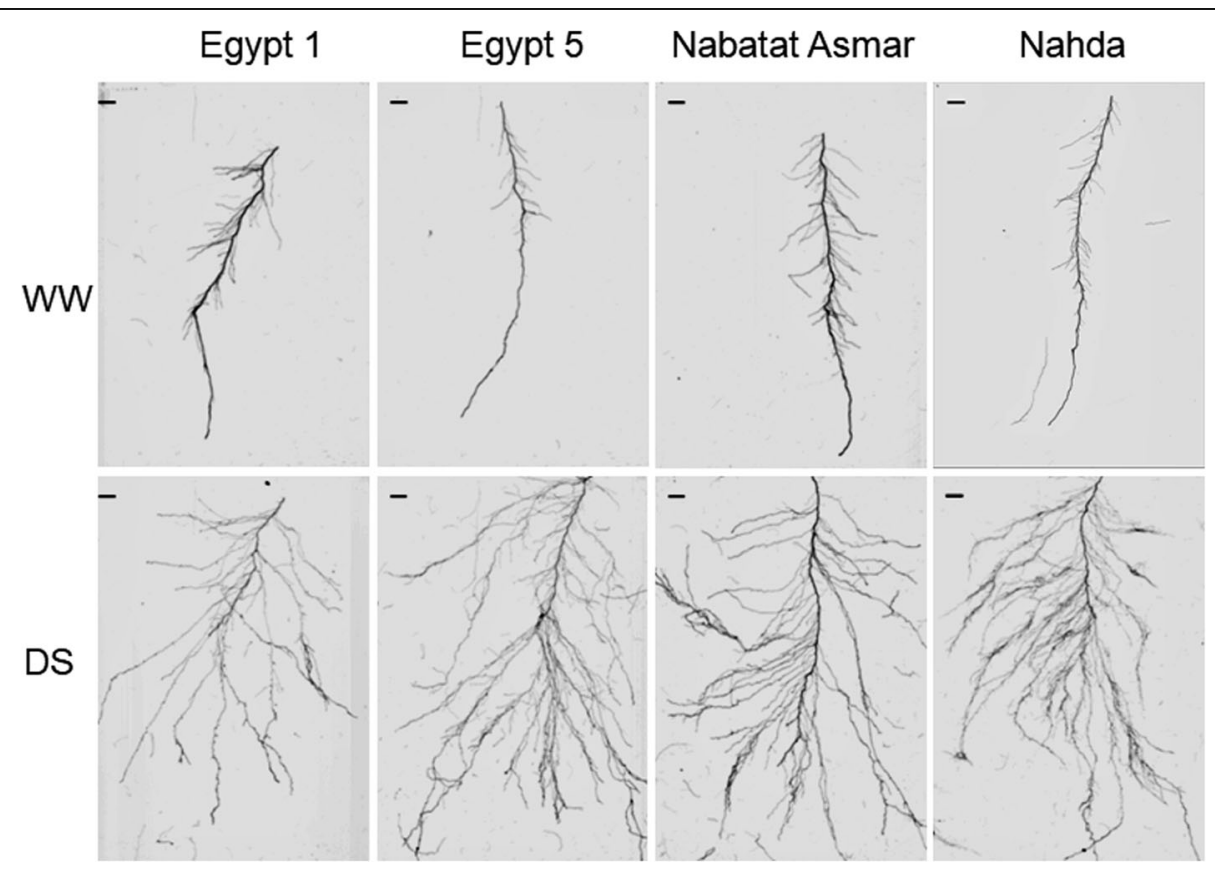

Fig. 6 Representative images of the apical $20 \mathrm{~cm}$ of nodal roots from well-watered (MW) and drought stressed (DS) plants. Scale bar represents $10 \mathrm{~mm}$ 
lateral root branching in apical (deepest $20 \mathrm{~cm}$ ) and basal (the rest of the root) nodal root segments (Fig. 7). Drought stress significantly increased large lateral root branching density especially in apical segments, and there was a significant cultivar $\mathrm{x}$ treatment interaction (Fig. 7, Table 2). The drought-induced increase in large lateral root branching density of the apical segment of nodal roots ranged from 3.0 (Nabatat Asmar) to 7.2-fold (Egypt 5). There was significant cultivar $\mathrm{x}$ treatment interaction for small lateral root branching density, but in this case the greater effect was on the basal segment (Table 2). Basal segments had greater small lateral root branching density than apical segments in all four cultivars (Fig. 7). Only Nahda had a significant increase in small lateral root branching density under drought stress, in both apical (3.2-fold) and basal segments (2.6-fold).

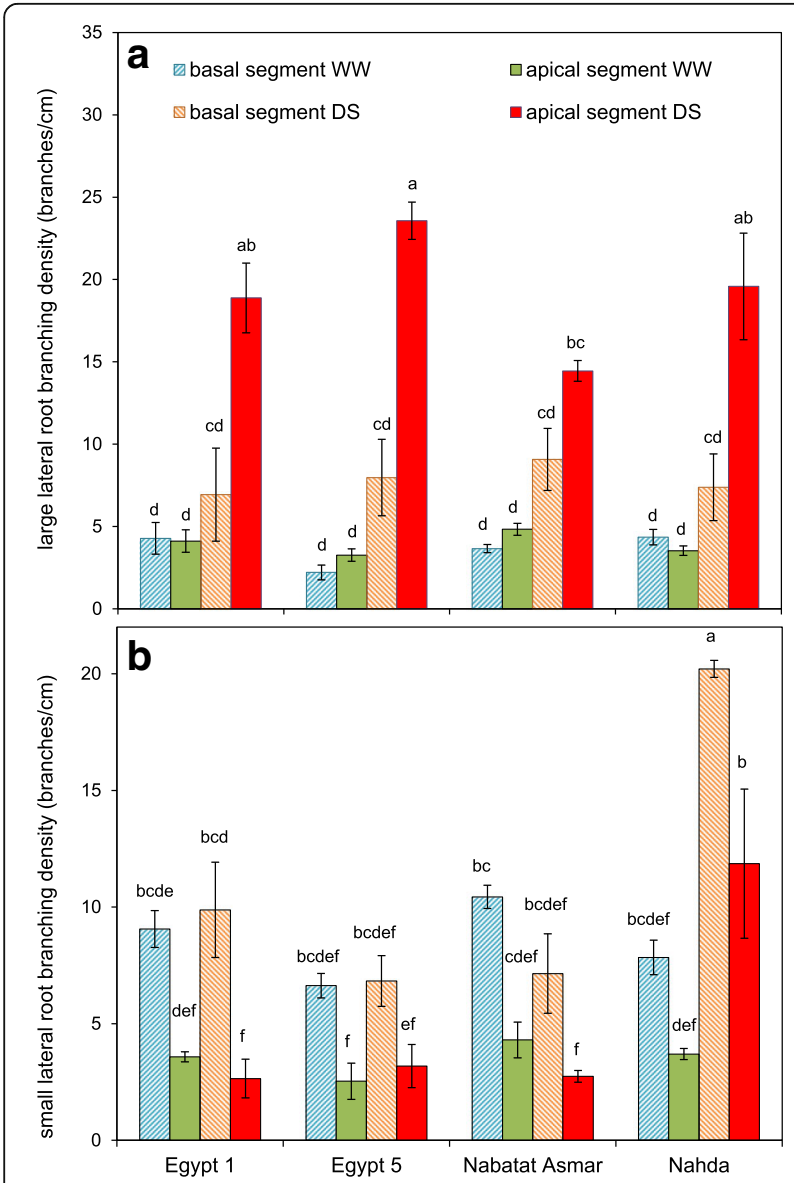

Fig. 7 Lateral root branching density basal and apical segments of well-watered (MW) and drought stressed (DS) nodal roots of four rice cultivars. The basal segment consisted of the entire nodal root except for the apical $20 \mathrm{~cm}$ segment, which was evaluated separately. a large lateral root branching density and $\mathbf{b}$ small lateral root branching density. Values shown are means of three replications \pm SE. Means with the same letter are not significantly different according to Tukey's Honest Significant Differences (HSD) test $(P \leq 0.05)$
Large lateral root length was significantly increased by drought to a similar extent in all cultivars, while small lateral root length was strongly affected by drought, cultivar and their interaction (Table 2, Fig. 8). Nahda displayed the greatest increase in small lateral root length (14-fold) in the apical segment in response to drought compared to well-watered plants (Fig. 8).

\section{Root Anatomy Responses to Drought Nodal Roots are Thinner and Have a More Lignified Stele} Under drought treatment, nodal root cross sectional area was 32\% (Nabatat Asmar) to 71\% (Egypt 1) less than that of well-watered treatment in the basal root segments, and $31.9 \%$ (Egypt 1) to 61.6\% (Egypt 5) less in the apical segments (Figs. 9 and 10a). The stele area near the root apex was not significantly affected by cultivar or treatment, but there was a significant treatment $\mathrm{x}$ cultivar interaction for basal segment stele area (Table 2), caused by a significantly larger stele under drought in Nabatat Asmar (Fig. 10b). Stele areas were preserved at the expense of cortical areas, so that they became a much greater proportion of the total cross-sectional area (Fig. 9). The mean proportion of cross-sectional area as stele was $5.8 \%$ and $13.07 \%$ for well-watered and drought stressed basal segments, and $6.54 \%$ and $15.31 \%$ for well-watered and drought stressed apical segments, respectively.

The number of late metaxylem vessels in basal and apical nodal root segments was significantly affected by cultivar, treatment, and their interaction (Fig. 10, Table 2). Egypt 1 displayed the greatest variation between treatments and sampling positions, with fewer vessels in apical than in basal segments, and fewer vessels in basal segments under drought. Theoretical axial water conductance was reduced by $66 \%$ under drought stress in basal segments of Egypt 1, driven by the number but not the median area (Additional file 5: Figure S4) of vessels. Egypt 5 under drought, in contrast, displayed reduced conductance of the apical segments, driven by both number and median area of vessels.

Drought stress led to a reduction in lignification (auto-fluorescence) of the epidermis, exodermis, and sclerenchyma in both basal and apical nodal root segments (Fig. 9). Likewise, the "spokes" of cortical cells separating aerenchyma lacunae lacked the lignification found in well-watered conditions and were no longer visible under UV illumination. We compared lignification patterns assessed by digital staining of LAT images with conventional histochemistry in nodal roots of one representative cultivar (Egypt 5) (Fig. 11, Additional file 6: Figure S5). The histochemical staining of nodal roots from dry soil by toluidine blue $\mathrm{O}$, Wiesner and Mäule stains confirmed that the sclerenchyma 


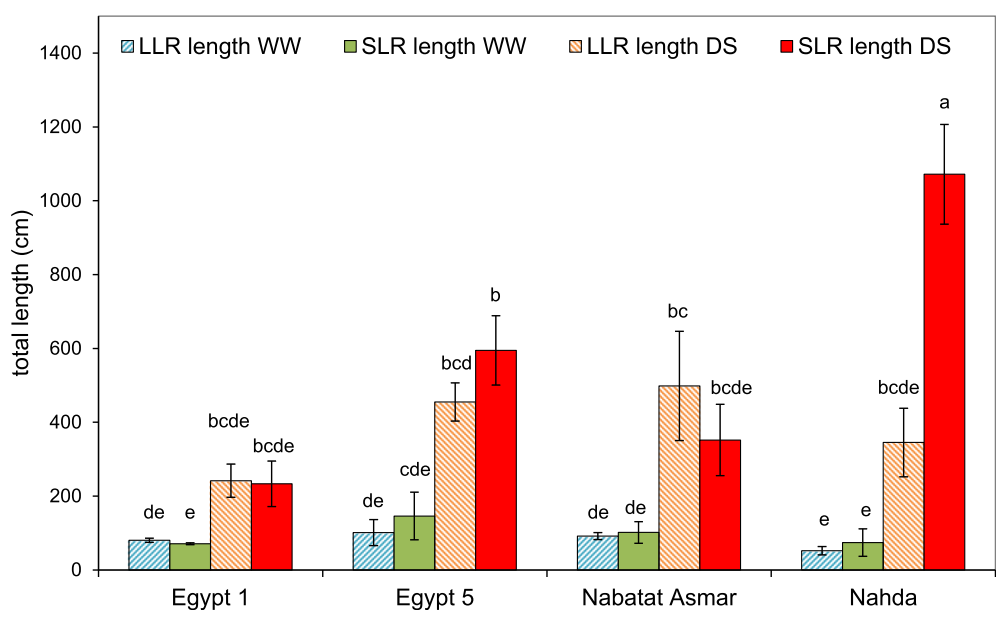

Fig. 8 Effect of drought stress on large and small lateral root lengths in four rice cultivars. Root lengths are for the apical (deepest) $20 \mathrm{~cm}$ nodal root segment. Values shown are means of three replications \pm SE. Means with the same letter are not significantly different according to Tukey's Honest Significant Differences (HSD) test $(P \leq 0.05)$

layer and the cortical tissue between aerenchyma lacunae lacked lignin, while stele tissue accumulated more lignin than nodal roots from wet soil.

\section{Anatomical Variation Along a Single Large Lateral Root}

Observation of the anatomy of large lateral roots revealed increasing cross-sectional area from the root base to the apex, especially under drought (Fig. 12, Additional file 7: Figure S6, Additional file 8: Figure S7). Despite their smaller cross-sectional area $\left(0.05-0.102 \mathrm{~mm}^{2}\right)$ compared with nodal roots $\left(0.087-0.53 \mathrm{~mm}^{2}\right)$, the anatomy of large lateral roots and nodal roots was very similar (compare Figs. 9 and 12). Lignification was assessed by digital staining, which detected lignin with red color (Additional file 9: Figure S8). Like nodal roots, large lateral roots showed lignification of sclerenchyma, endodermis and inner cortical cells under well-watered conditions, while roots from drought stressed plants had less lignification outside the stele and more lignification in the stele in the older parts of the lateral root (Fig. 12, Additional file 9: Figure S8). Aerenchyma was observed in both treatments, but in drought stressed roots, it was less developed in medial segments (Fig. 12). Large lateral roots typically had a single late metaxylem vessel (Fig. 12, Additional file 8: Figure S7).

\section{Discussion}

The Egyptian cultivars displayed a wide variation in root phenotypes when grown in large mesocosms. The accessions represent a variety of backgrounds (Additional file 1: Table S1) which might explain some of the variation in root traits. For example, varietal group Japonica cultivars are typically considered to have deeper and thicker roots than those of Indica, facilitating deep soil penetration and water acquisition in upland conditions (Gowda et al. 2011). In this study, the thickest nodal roots in this study were indeed Japonica cultivars, i.e. Yabani 47 and Nabatat Asmar. However, the two cultivars with the greatest root depth were Japonica (Nabatat Asmar) and indica (Egypt 5), and the shortest was Japonica (Yabani 47, Fig. 1).

Correlation among root thickness-related anatomical traits has been previously reported for rice and maize (Uga et al. 2008; Uga et al. 2009; Burton et al. 2015; Vejchasarn et al. 2016). In previous studies of an F3 population from a cross of IR64 (Indica) and Kinandang Patong (Japonica) (Uga et al. 2008) and a collection of 59 diverse accessions of cultivated rice (Uga et al. 2009), high correlations were found among stele area, total area of late metaxylem vessels, and number of metaxylem vessels. Here we confirmed correlations between root cross sectional area and stele area, and between both those traits and total metaxylem vessel area, but not with median metaxylem area or number of metaxylem vessels (Table 2). Variation related to cross-sectional area could be partially explained by varietal group differences, but clearly there is wide variation within groups as well.

There were several unexpected correlations between architectural and anatomical traits, e.g. metaxylem vessel number was positively correlated with both small and large lateral root length, but negatively correlated with maximum root depth (Table 1). In a previous study of 15 rice cultivars, metaxylem vessel number was significantly correlated with small lateral root length under low phosphorus, but not high phosphorus conditions (Vejchasarn et al. 2016). Studies with a greater number of genotypes would be required to resolve whether these correlations are typical of rice germplasm and have functional significance. 


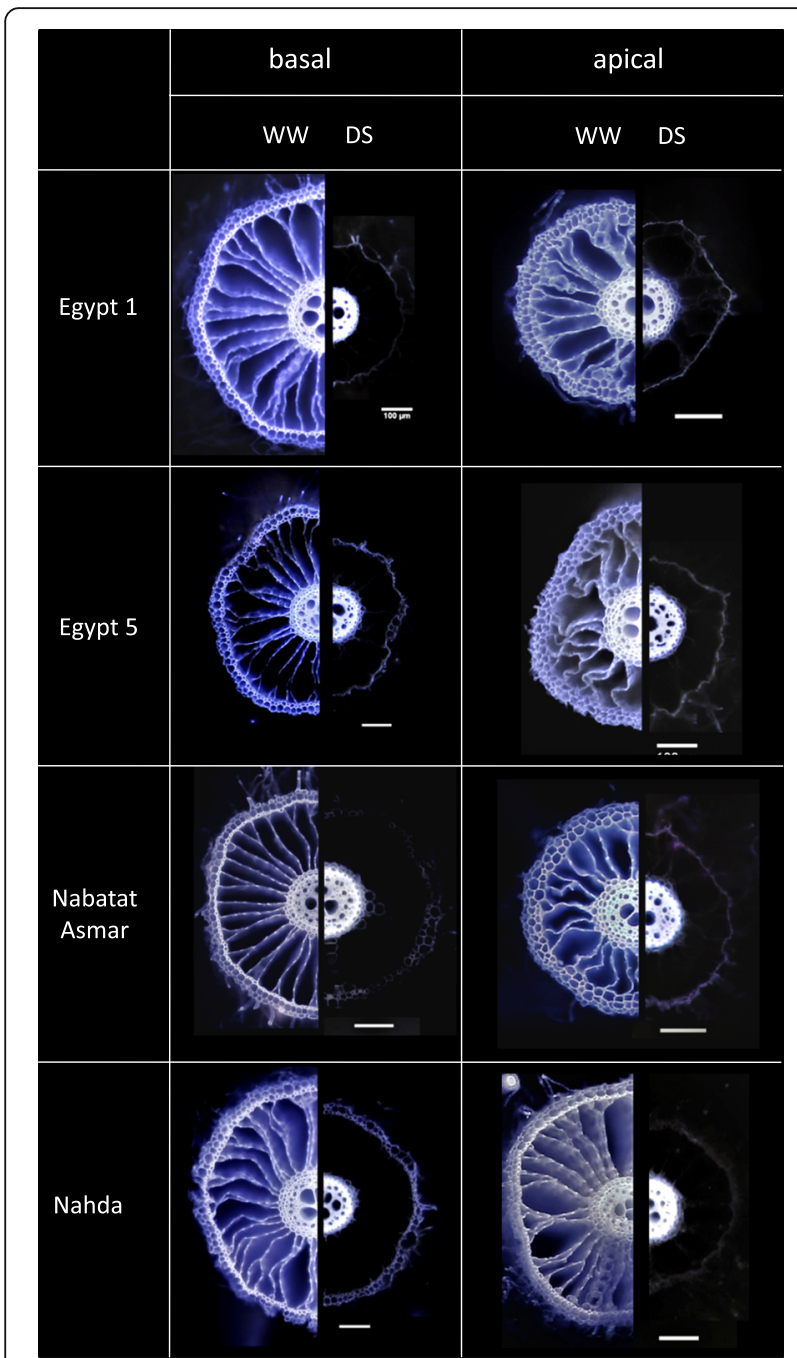

Fig. 9 Laser Ablation Tomography (LAT) images of rice nodal root segments sampled $20 \mathrm{~cm}$ from the root base (basal) and $10 \mathrm{~cm}$ from nodal root tip (apical), under well-watered (WW) and drought stressed (DS) conditions. Each scale bar represents $100 \mu \mathrm{m}$

In this study, most root traits were plastic, i.e. they responded to reduced moisture availability, and in some cases the extent of the change depended on the cultivar (Table 2). Under drought, nodal root number was reduced to a similar extent in all four cultivars (Fig. 5) but nodal roots branched extensively in the deeper part of the mesocosm where more moisture was available (Figs. 6, 7 and 8). Total length per nodal root of both large and small lateral roots increased in the apical segments of nodal roots, resulting primarily from increased branching density and elongation of large lateral roots (Figs. 6, 7 and 8). Just one cultivar, Nahda, displayed increased small lateral root branching density under drought, and this occurred mostly in the basal segment exposed to drier medium (Fig. 7).
Lateral root branching in response to spatially variable water availability has been termed "hydropatterning" (Bao et al. 2014). While the term was coined to describe radially variable lateral rooting patterns when different sides of axial roots were exposed to differential moisture, plants have long been known to respond to locally available limiting resources with greater branching (Gowda et al. 2011; Rich and Watt 2013). In rice fields subjected to periodic drawdown of water levels, water is generally more available at depth. While spatial variation in lateral branching responses of deep nodal roots under stratified moisture availability has not been described in detail, others have suggested that lateral root proliferation could be important for drought tolerance in rice (Henry et al. 2011; Kano et al. 2011; Kano-Nakata et al. 2013; Tran et al. 2015). In one study of four chromosome segment substitution lines, the line that performed best under drought was the one with greatest lateral root proliferation (Kano et al. 2011). In a more recent study, root branching plasticity at different depths was investigated in 20 genotypes in the field (Sandhu et al. 2016). The authors found a positive relationship between deep root length density (driven by all root classes) and yield stability across water regimes and management strategies. Our work demonstrates that this type of plasticity can be measured in a controlled environment where it is possible to recover the entire root system, and suggests that plasticity of lateral root branching specifically in deep, higher-moisture soil could be a potential breeding objective.

Nodal roots and large lateral roots that are exposed to drought experience variation in water availability along their axes, with potential for moisture loss from the shallower portion of the root to dry soil along a water potential gradient. In this study, both the basal and apical segments of nodal roots altered their anatomical structure and composition in response to drought. Basal segments of roots exposed to drought were much thinner than those in well-watered conditions (Fig. 10). The reduction in cross-sectional area resulted from a much smaller cortex, since the stele was not significantly affected by drought (Fig. 10). Similar results were reported in anatomical evaluations of basal segments of nodal roots of Indica rice varieties exposed to wellwatered or drought conditions for 30 days in two greenhouse studies (Kadam et al. 2015; Kadam et al. 2017). We also observed anatomical variation along large lateral root axes, but in this case the apical segments, which were in a wetter part of the growth medium, were similar to large lateral root segments from well-watered treatments, while the older parts of the root displayed anatomical changes similar to those of the nodal roots (Fig. 12), supporting a role for these roots in nutrient and water uptake from the deeper soil strata. 

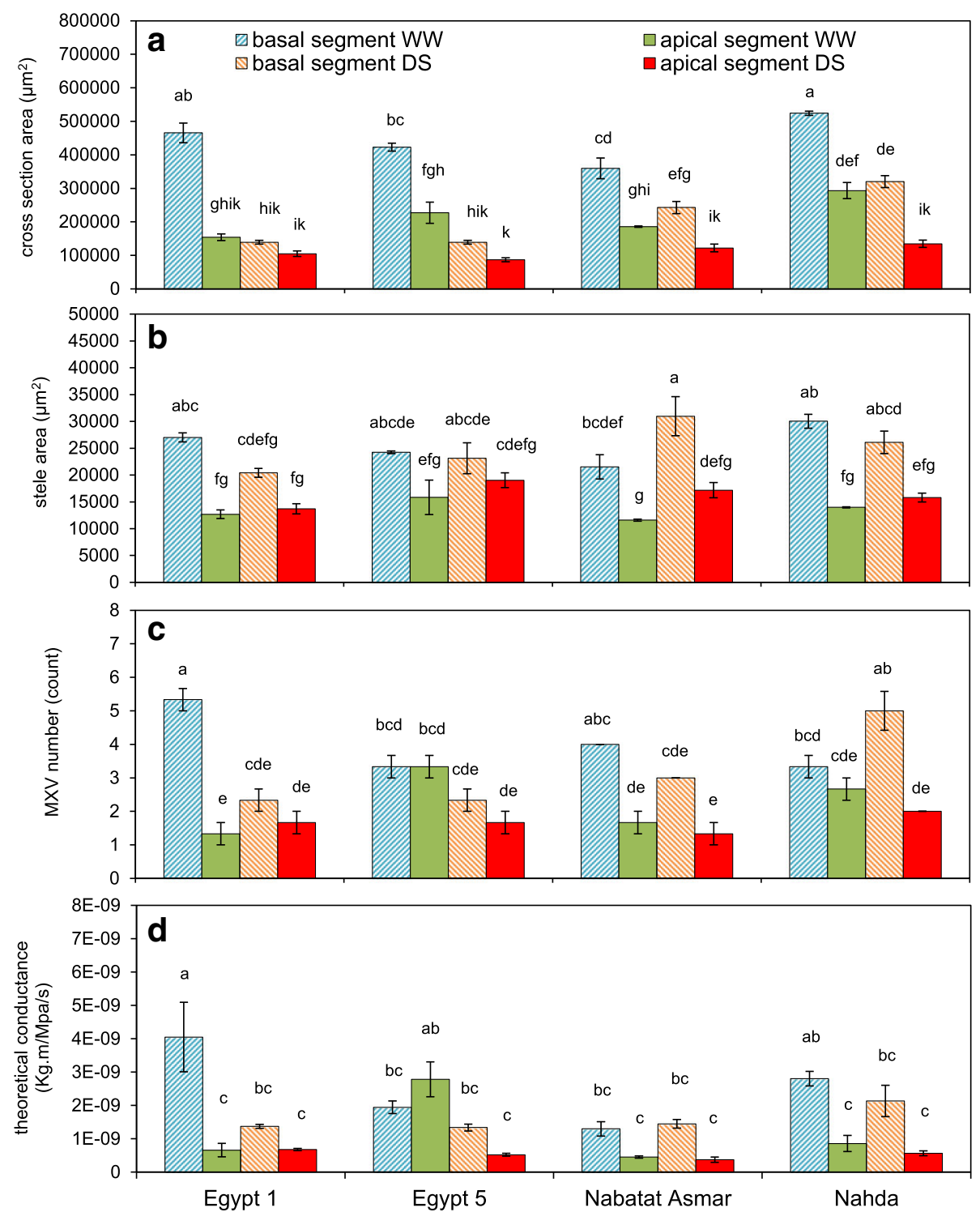

Fig. 10 Effects of drought stress on anatomy of nodal roots of four rice cultivars grown under well-watered (WW) and drought-stressed (DS) conditions. Basal segments were sampled from $20 \mathrm{~cm}$ from the root base and apical segments were sampled $10 \mathrm{~cm}$ from the root tips. a cross section area; $\mathbf{b}$ stele area; $\mathbf{c}$ number of late metaxylem vessels; $\mathbf{d}$ theoretical axial conductance. Values shown are means of three replications $\pm S E$. Means with the same letter are not significantly different according to Tukey's Honest Significant Differences (HSD) test $(P \leq 0.05)$

Lignification patterns in rice roots were revealed by ultraviolet (UV) illumination provided by the laser used for ablation of root tissue. UV has previously been used to visualize root anatomy based on the ability of plant cells to autofluoresce (Rebouillat et al. 2009). We adapted this method for use with laser ablation tomography, demonstrated the coincidence of UV-induced autofluorescence with conventional Maüle and phloroglucinol staining, and presented a method for digitally processing the laser ablation tomography images for enhanced visualization of lignification patterns in two species (Figs. 9, 11 and 12, Additional file 3: Figure S2 and Additional file 6: Figure S5).
Basal and apical segments of nodal roots exposed to drought displayed more lignification of the stele and less lignification of the cortex and outer layers (epidermis, exodermis, and sclerenchyma) compared with corresponding segments from well-watered plants (Fig. 9). Similar responses were found in large lateral roots, but only in the basal segments (Fig. 12). Apical segments of large lateral roots lacked an obvious sclerenchyma layer and displayed fairly uniform lignin distribution across cell types with the exception of the early metaxylem vessels. To our knowledge, there have been no previous reports of reduced lignin in outer cell layers of rice roots and increased lignification of the stele under drought. 


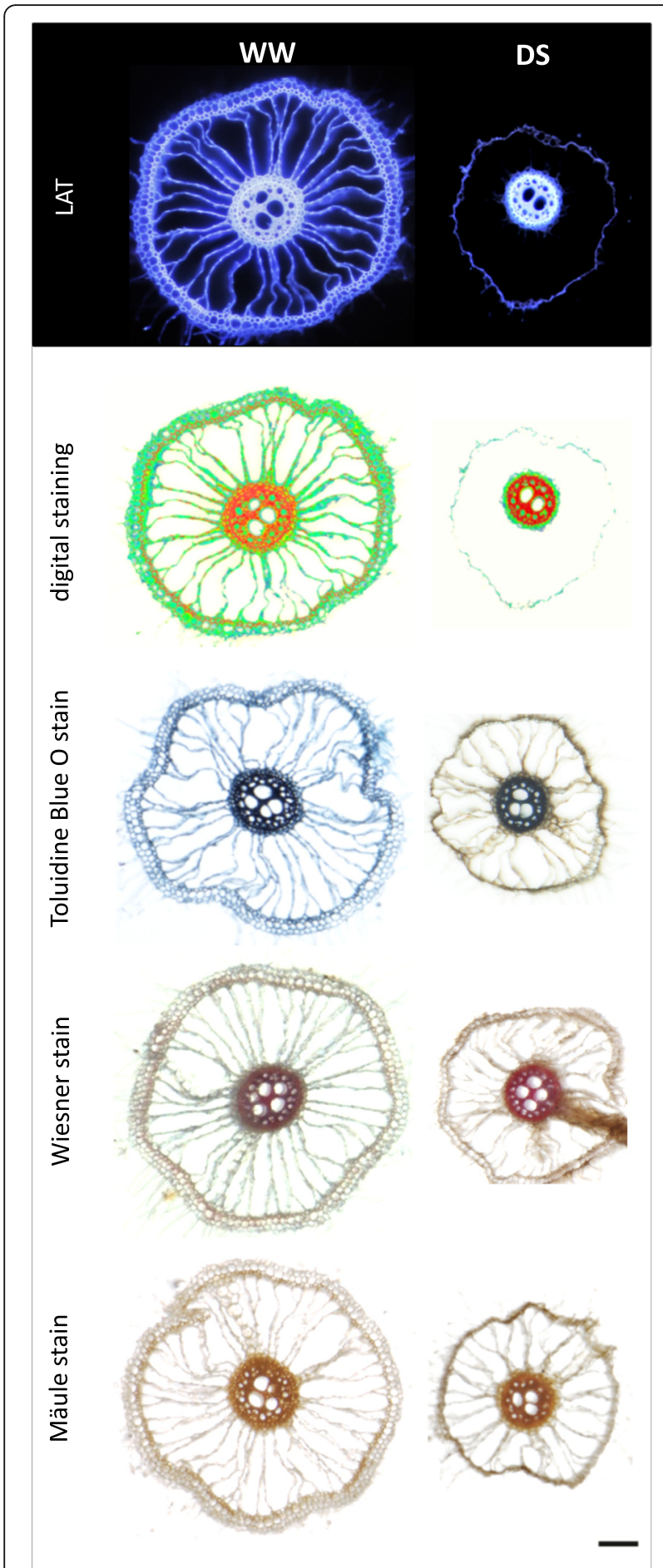

Fig. 11 Lignin distribution pattern in response to drought stress (DS) in basal nodal root segments of cultivar Egypt 5. Variation in lignin deposition in response to DS were visualized by, from top, LAT, LAT plus digital staining, and three lignin-specific histochemical stains. Horizontal bars represent $100 \mu \mathrm{m}$
However, suberization was reported to decline in the sclerenchyma and increase in the endodermis during drought for several rice cultivars grown in the greenhouse and field (Henry et al. 2012). Suberization and lignification of the outer cell layers of rice are typically correlated (Enstone et al. 2002; Kotula et al. 2009).

The distribution and environmental responsiveness of suberized and lignified endodermal and outer cell layers suggest a role protecting root function in waterlogged and drying soils. Their importance for development of a barrier to radial oxygen loss during waterlogging is well-established (Colmer 2003). However, greater lignification and suberization of the exodermis and endodermis in stagnant solutions relative to aerated solutions were not related to hydraulic conductivity, although permeability to $\mathrm{NaCl}$ was significantly reduced (Garthwaite et al. 2006; Ranathunge et al. 2011). Greater thickening of sclerenchyma layers was found in irrigated compared with submerged rice roots (Mostajeran and Rahimi-Eichi 2008), which is probably related to lignification. Kondo et al. (2000) suggested that thickening of the sclerenchyma layer could play a role in structural support when the root is exposed to drying, hardening soil. In other species, e.g. sorghum and maize, the exodermis was observed to become more lignified with drought stress (Enstone et al. 2002). The fact that rice behaves differently, fortifying the endodermis and stele rather than the outer cell layers during drought, may be related to its adaptation to waterlogged conditions, including the presence of extensive aerenchyma. Fortification of the stele would maintain root function as a conduit for water and nutrient movement from lateral roots, while preventing loss of ions and water to the soil.

Basal segments of nodal roots from all four cultivars were thinner when exposed to drought, an effect that has been observed in other studies (Kadam et al. 2015; Kadam et al. 2017). The basal segments of large lateral roots were also thinner under drought, but these roots became thicker as they elongated into medium that had increasing moisture with depth (Additional file 7: Figure S6). Thinner roots may be beneficial for soil exploration because they have less nutrient and carbon cost per unit length, increasing resources available for root elongation into new soil domains (Lynch 2013), and they can explore small pores and crevices in the soil (Bengough et al. 2011). On the other hand, thicker roots have been associated with better soil penetration ability, which is important for root growth into hardened soils or through hardpans under drought conditions (Clark et al. 2008; Gowda et al. 2011; Lynch et al., 2014). In rice, these functions may depend on root class, i.e. thicker nodal roots may penetrate harder soils, while thinner lateral roots may explore fissures and pores. 

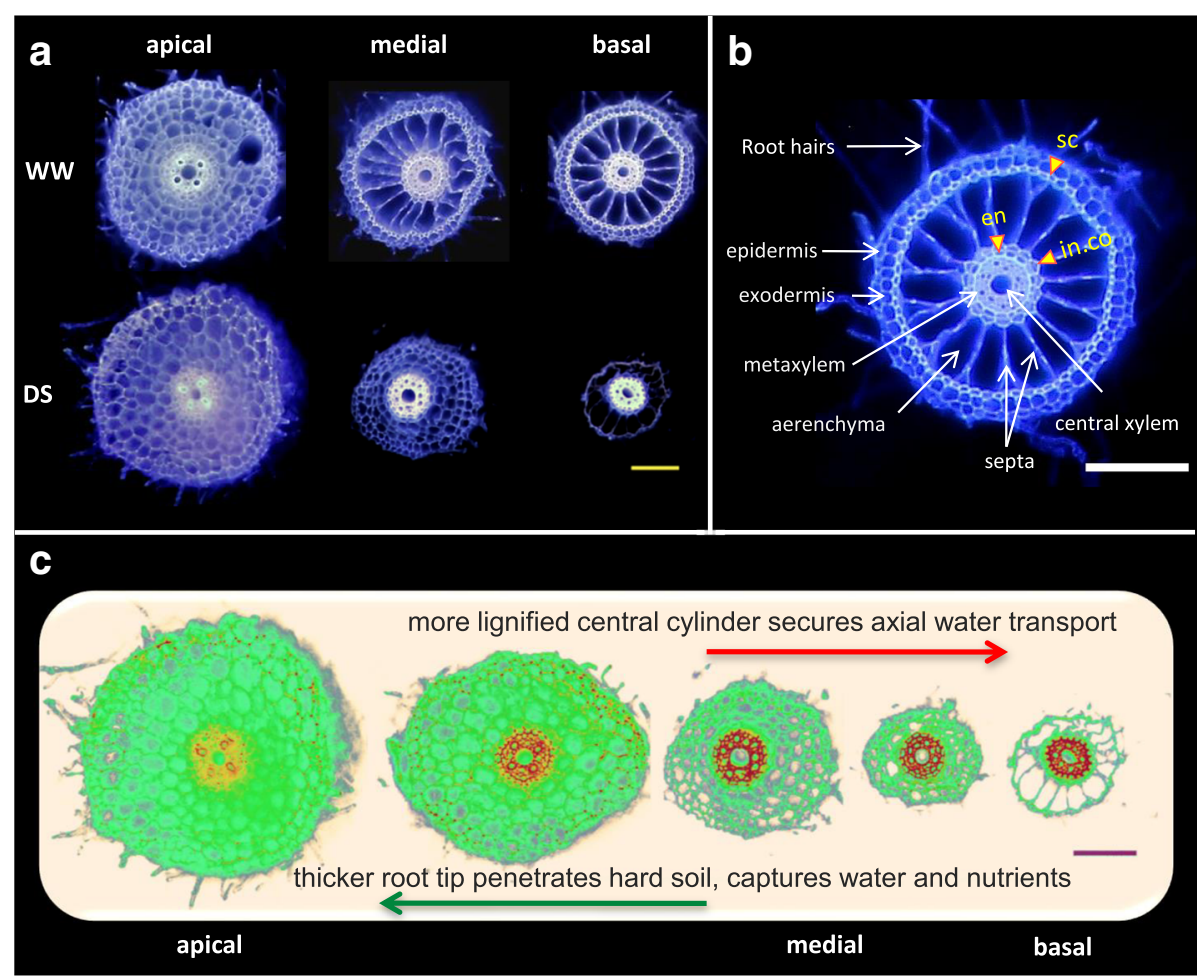

Fig. 12 Drought stress (DS) impact on large lateral root (LLR) anatomy of Egypt 1. a Laser Ablation Tomography images of LLR segments sampled at three different locations: apical (2-5 mm from root tip), medial (close to the midpoint of the root), and basal (2-5 $\mathrm{mm}$ from point of attachment to nodal root axis). $\mathbf{b}$ anatomy of basal segment of LLR after 6 weeks in well-watered (WW) conditions showing lignification of sclerenchyma (sc), inner cortical cells (in. co), and endodermis (en). c model suggesting functions of observed anatomical variation using digitally stained images of Egypt 1. Red color reveals heavy lignin deposition pattern in the stele of the basal segments. Scale bars represent $100 \mu \mathrm{m}$

Drought did not significantly affect apical stele area, and in one cultivar, Nabatat Asmar, it significantly increased basal stele area (Table 2, Fig. 10), so that the proportion of cross-sectional area as stele was significantly increased in all four cultivars. In another study, stele area was observed to increase during drought in both the greenhouse and the field (Henry et al. 2012). Conservation of stele area under drought could be beneficial for maintaining root penetration ability. In maize, stele area was positively associated with root tensile strength (Chimungu et al. 2015). In rice, maintenance of stele area and heavy fortification of the stele with lignin during drought could help roots to continue to grow as soils become harder.

The effect of drought on number of late metaxylem vessels varied among cultivars, and the median metaxylem vessel area varied in the basal segment under drought (Fig. 10, Additional file 5: Figure S4). Kadam et al. (2015) found no significant effect of drought on metaxylem diameter or number at several nodal root positions in three rice cultivars, but others have found that some rice cultivars had smaller vessels when exposed to drought (Yambao et al. 1992; Mostajeran and Rahimi-Eichi 2008;
Henry et al. 2012). Smaller vessels would be expected protect the xylem from cavitation, moderate water movement to the shoot, and help maintain a moist rhizosphere for continued root growth and water and nutrient uptake. Plasticity of vessel size could be useful to provide these advantages under drought while permitting adequate water transport to the shoot to support rapid growth under well-watered conditions.

Cultivated rice displays wide variation for root architectural and anatomical traits, as well as variation for plasticity of these traits. We propose that under moderate progressive drought and under reduced water-usage management strategies, where water potential in the upper soil layers declines but more moisture is available at depth, rice crops will benefit from deep soil exploration via extension and branching of large lateral roots, while minimizing development of additional nodal roots. Patterns of lignification and suberization would additionally help to maintain water uptake from deep soil horizons while minimizing losses to dry soil in the shallower layers. These traits require further examination to confirm their utility in agricultural fields. 


\section{Additional files}

Additional file 1: Table S1. Egyptian cultivars used in the study, with accession numbers and flowering times from the U.S. National Plant Germplasm System, and subpopulation assignments. (DOCX 21 kb)

Additional file 2: Figure S1. Xylem anatomy of 11 Egyptian rice cultivars grown in the greenhouse under well-watered conditions: a median metaxylem vessel area and $\mathbf{b}$ metaxylem vessel number. Values shown are means of three replications \pm SE. Means with the same letter are not significantly different according to Tukey's Honest Significant Differences (HSD) test $(P \leq 0.05)$. (PPTX $53 \mathrm{~kb})$

Additional file 3: Figure S2. a Laser Ablation Tomography (LAT) image of a sweet corn nodal root segment sampled $15 \mathrm{~cm}$ from the root base, and $\mathbf{b}$ the same image digitally stained. Lignin deposition is indicated as red colored areas. Scale bar represents $100 \mu \mathrm{m}$. (PPTX $1.29 \mathrm{mb}$ )

Additional file 4: Figure S3. Schematic representation of mesocosms used for rice growth and imposition of drought. Volumetric wate content $(\theta v)$ of the medium in the upper and lower parts of the mesocosms are indicated. These measurements were recorded using TDR probes after 6 weeks growth, including the final 4 weeks without additional water. Probes were inserted $25 \mathrm{~cm}$ from the surface under wellwatered conditions, and at $25 \mathrm{~cm}$ and $100 \mathrm{~cm}$ depth for drought stress treatments. Values shown are ranges of three replications. (PPTX $257 \mathrm{~kb}$ )

Additional file 5: Figure S4. Effects of drought stress on median metaxylem vessel area in basal segments of nodal roots of four rice cultivars grown under drought-stressed (DS) conditions. Values shown are means of three replications \pm SE. Means with the same letter are not significantly different according to Tukey's Honest Significant Differences (HSD) test $(P \leq 0.05)$. There were no significant differences in median metaxylem vessel areas in apical segments of DS plants or in any segments of well-watered plants. (PPTX $42 \mathrm{~kb}$ )

Additional file 6: Figure S5. Nodal root cross sections taken from basal segments and stained with Weisner stain show variation in lignin deposition in the stele and endodermis between well-watered (MW) and drought stress (DS) conditions. Black arrowheads indicate the endodermis. (PPTX $1.67 \mathrm{mb}$ )

Additional file 7: Figure S6. Cross sectional areas of large lateral roots of cultivar Egypt 1 at distal, medial and basal positions. Values shown are means of three replications \pm SE. Means with the same letter are not significantly different according to Tukey's Honest Significant Differences (HSD) test ( $P \leq 0.05)$. (PPTX $42 \mathrm{~kb}$ )

Additional file 8: Figure S7. LAT (a) and digitally stained (b) images of a basal segment cross-section of a large lateral root under well-watered conditions showing lignification of sclerenchyma (sc), inner cortical area (in.co) and endodermis (en). Horizontal bars represent $100 \mu \mathrm{m}$. (PPTX 599 kb)

Additional file 9: Figure S8. a Portion of scanned root system of Egypt 1 grown under drought stress with large lateral root (LLR) anatomical sampling positions indicated. $\mathbf{b}$ LAT images from a single LLR sampled from apical (1) to basal (5) positions. Scale bar in $\mathbf{b}$ represents $100 \mu \mathrm{m}$. (PPTX $535 \mathrm{~kb})$

\section{Abbreviations}

CPD: Critical point dryer; DS: Drought-stressed; HSD: Honest significant difference; LAT: Laser ablation tomography; LLR: Large lateral root; LRBD: Lateral root branching density; SLR: Small lateral root; TDR: Time domain reflectometry; UV: Ultraviolet; WW: Well-watered

\section{Acknowledgements}

We thank Jenna Reeger and Amelia Henry for useful comments on the manuscript, and Robert Snyder and Jenna Reeger for technical assistance.

\section{Funding}

We thank the Binational Fulbright Commission in Egypt and Dr. Haneya Al Etrieby of the Agricultural Development Fund, Ministry of Agriculture and Land Reclamation, Egypt, for supporting Dr. Hazman's visit to Penn State. This material is based upon work that is supported by the National Institute of Food and Agriculture, U.S. Department of Agriculture, Hatch project PENO4582, accession \# 1005492.

\section{Availability of data and materials}

The datasets used and/or analyzed during the current study are available from the corresponding author on reasonable request.

\section{Authors' contributions}

$\mathrm{KB}$ and $\mathrm{MH}$ designed the experiments, $\mathrm{MH}$ performed the experiments and analyzed the data, $\mathrm{MH}$ and $\mathrm{KB}$ interpreted the data and wrote the manuscript. Both authors read and approved the manuscript.

Ethics approval and consent to participate

Not applicable.

\section{Consent for publication}

Not applicable.

\section{Competing interests}

The authors declare that they have no competing interests.

\section{Publisher's Note}

Springer Nature remains neutral with regard to jurisdictional claims in published maps and institutional affiliations.

\section{Author details}

${ }^{1}$ Department of Plant Science, The Pennsylvania State University, 102 Tyson Building, University Park, University Park, PA 16802-4200, USA. ${ }^{2}$ Agricultural Genetic Engineering Research Institute (AGERI), Agricultural Research Centre (ARC), 9 Gamma St., Giza 12619, Egypt.

Received: 4 August 2018 Accepted: 24 October 2018

Published online: 04 December 2018

\section{References}

Bao Y, Aggarwal P, Robbins NE et al (2014) Plant roots use a patterning mechanism to position lateral root branches toward available water. Proc Natl Acad Sci. https://doi.org/10.1073/pnas.1400966111

Bengough AG, McKenzie BM, Hallett PD, Valentine TA (2011) Root elongation, water stress, and mechanical impedance: a review of limiting stresses and beneficial root tip traits. J Exp Bot 62:59-68. https://doi.org/10.1093/jxb/erq350

Burton AL, Johnson J, Foerster J et al (2015) QTL mapping and phenotypic variation of root anatomical traits in maize (Zea mays L.). Theor Appl Genet. https://doi.org/10.1007/s00122-014-2414-8

Chimungu JG, Loades KW, Lynch JP (2015) Root anatomical phenes predict root penetration ability and biomechanical properties in maize (Zea mays). J Exp Bot 66:3151-3162. https://doi.org/10.1093/jxb/erv121

Clark L, Cope R, Whalley W et al (2002) Root penetration of strong soil in rainfed lowland rice: comparison of laboratory screens with field performance. $F$ Crop Res 76:189-198

Clark L, Price AH, Steele KA, Whalley WR (2008) Evidence from near-isogenic lines that root penetration increases with root diameter and bending stiffness in rice. Funct Plant Biol 35:1163-1171. https://doi.org/10.1071/fp08132

Colmer TD (2003) Long-distance transport of gases in plants: a perspective on internal aeration and radial oxygen loss from roots. Plant Cell Environ 26:17-36

Enstone DE, Peterson CA, Ma F (2002) Root endodermis and exodermis: structure, function, and responses to the environment. J Plant Growth Regul 21:335351. https://doi.org/10.1007/s00344-003-0002-2

Garthwaite AJ, Steudle E, Colmer TD (2006) Water uptake by roots of Hordeum marinum: formation of a barrier to radial $0-2$ loss does not affect root hydraulic conductivity. J Exp Bot 57:655-664

Gowda VRP, Henry A, Yamauchi A et al (2011) Root biology and genetic improvement for drought avoidance in rice. F Crop Res 122:1-13

Hazman M, Hause B, Eiche E et al (2015) Increased tolerance to salt stress in OPDA-deficient rice ALLENE OXIDE CYCLASE mutants is linked to an increased ROS-scavenging activity. J Exp Bot 66:3339-3352

Henry A, Cal AJ, Batoto TC et al (2012) Root attributes affecting water uptake of rice (Oryza sativa) under drought. J Exp Bot 63:4751-4763. https://doi.org/10. 1093/jxb/ers150

Henry A, Gowda VRP, Torres RO et al (2011) Variation in root system architecture and drought response in rice (Oryza sativa): phenotyping of the OryzaSNP panel in rainfed lowland fields. F Crop Res 120:205-214 
Kadam NN, Tamilselvan A, Lawas LMF et al (2017) Genetic control of plasticity in root morphology and anatomy of Rice in response to water deficit. Plant Physiol 174:2302 LP-2302315

Kadam NN, Yin X, Bindraban PS et al (2015) Does morphological and anatomical plasticity during the vegetative stage make wheat more tolerant of water deficit stress than Rice? Plant Physiol 167:1389-1401. https://doi.org/10.1104/ pp.114.253328

Kamoshita A, Wade LJ, Yamauchi A (2000) Genotypic variation in response of Rainfed lowland Rice to drought and Rewatering. III. Water extraction during the drought period. Plant Prod Sci 3:189-196. https://doi.org/10.1626/pps.3.189

Kano M, Inukai Y, Kitano H, Yamauchi A (2011) Root plasticity as the key root trait for adaptation to various intensities of drought stress in rice. Plant Soil 342: $117-128$

Kano-Nakata M, Gowda VRP, Henry A et al (2013) Functional roles of the plasticity of root system development in biomass production and water uptake under rainfed lowland conditions. F Crop Res 144:288-296. https://doi.org/10.1016/j. fcr.2013.01.024

Kano-Nakata M, Inukai Y, Wade $\amalg$ et al (2011) Root development, water uptake, and shoot dry matter production under water deficit conditions in two CSSLS of Rice: functional roles of root plasticity. Plant Prod Sci 14:307-317. https://doi.org/10.1626/pps.14.307

Kondo M, Aguilar A, Abe J, Morita S (2000) Anatomy of nodal roots in tropical upland and lowland rice varieties. Plant Prod Sci 3:437-445

Kotula L, Ranathunge K, Schreiber L, Steudle E (2009) Functional and chemical comparison of apoplastic barriers to radial oxygen loss in roots of rice (Oryza sativa L.) grown in aerated or deoxygenated solution. J Exp Bot 60:21552167. https://doi.org/10.1093/jxb/erp089

Lynch J, Chimungu J, Brown K (2014) Root anatomical phenes associated with water acquisition from drying soil: targets for crop improvement. J Exp Bot 65:6155-6166

Lynch JP (2013) Steep, cheap and deep: an ideotype to optimize water and N acquisition by maize root systems. Ann Bot 112:347-357. https://doi.org/10. 1093/aob/mcs293

Lynch JP (2014) Root phenes that reduce the metabolic costs of soil exploration: opportunities for 21st century agriculture. Plant Cell Environ 38:1775-1784. https://doi.org/10.1111/pce.12451

Lynch JP (2018) Rightsizing Root Phenotypes for Drought resistance. J Exp Bot. https://doi.org/10.1093/jxb/ery048

Morita MT, Kato T, Nagafusa K et al (2002) Involvement of the vacuoles of the endodermis in the early process of shoot gravitropism in Arabidopsis. Plant Cell 14:47-56

Mostajeran A, Rahimi-Eichi V (2008) Drought stress effects on root anatomical characteristics of rice cultivars (Oryza sativa L.). Pakistan J Biol Sci 11:2173-2183

Pradhan Mitra P, Loqué D (2014) Histochemical staining of Arabidopsis thaliana secondary Cell Wall elements. J Vis Exp:51381. https://doi.org/10.3791/51381

Ranathunge K, Lin J, Steudle E, Schreiber L (2011) Stagnant deoxygenated growth enhances root suberization and lignifications, but differentially affects water and $\mathrm{NaCl}$ permeabilities in rice (Oryza sativa L.) roots. Plant Cell Environ 34:1223-1240. https://doi.org/10.1111/j.1365-3040.2011.02318.x

Rebouillat J, Dievart A, Verdeil JL et al (2009) Molecular genetics of rice root development. Rice 2:15-34. https://doi.org/10.1007/s12284-008-9016-5

Rich SM, Watt M (2013) Soil conditions and cereal root system architecture: review and considerations for linking Darwin and weaver. J Exp Bot 64:1193-1208. https://doi.org/10.1093/jxb/ert043

Sandhu N, Raman KA, Torres RO et al (2016) Rice root architectural plasticity traits and genetic regions for adaptability to variable cultivation and stress conditions. Plant Physiol 171:2562 LP-2562576

Siopongco JD, Yamauchi A, Salekdeh H et al (2005) Root growth and water extraction response of doubled-haploid Rice lines to drought and Rewatering during the vegetative stage. Plant Prod Sci 8:497-508. https://doi.org/10.1626/pps.8.497

Sosa J, Huber D, Weld B, Fraser H (2014) Development and application of MIPARTM: a novel software package for two- and three-dimensional microstructural characterization. Integr Mater 3:10. doi: https://doi.org/10. 1186/2193-9772-3-10

Suralta RR, Inukai Y, Yamauchi A (2010) Dry matter production in relation to root plastic development, oxygen transport, and water uptake of rice under transient soil moisture stresses. Plant Soil 332:87-104. https://doi.org/10.1007/ s11104-009-0275-8

Tran T, Kano-Nakata M, Suralta R et al (2015) Root plasticity and its functional roles were triggered by water deficit but not by the resulting changes in the forms of soil N in rice. Plant Soil 386:65-76. https://doi.org/10.1007/ s11104-014-2240-4

Tyree MT, Ewers FW (2018) The hydraulic architecture of trees and other woody plants. New Phytol 119:345-360. https://doi.org/10.1111/1.1469-8137.1991.tb00035.x

U.S. Department of Agriculture FAS (2018) World agricultural production, p 31

Uga Y, Ebana K, Abe J et al (2009) Variation in root morphology and anatomy among accessions of cultivated rice (Oryza sativa L.) with different genetic backgrounds. Breed Sci 59:87-93

Uga Y, Okuno K, Yano M (2008) QTLs underlying natural variation in stele and xylem structures of rice root. Breed Sci 58:7-14

Vejchasarn P, Lynch JP, Brown KM (2016) Genetic variability in phosphorus responses of Rice root phenotypes. Rice. https://doi.org/10.1186/s12284-016-0102-9

Wally A, Beillard MJ (2018) Egypt Grain and Feed Annual 2018. Wheat is up; Corn is steady, Egyptian Government Restricts Rice Planted Area. Foreign Agric Serv 2018:1-11

Wassmann R, Jagadish SVK, Heuer S, et al. (2009) Climate Change Affecting Rice Production: The Physiological and Agronomic Basis for Possible Adaptation Strategies. Adv Agron 101:59-122. doi: https://doi.org/10.1016/S00652113(08)00802-X

Yambao EB, Ingram KT, Real JG (1992) Root xylem influence on the water relations and drought resistance of rice. J Exp Bot 43:925-932

Yoshida S, Forno DA, Bhadrachalam A (1971) Zinc deficiency of the rice plant on calcareous and neutral soils in the philippines. Soil Science and Plant Nutrition 17 (2):83-87

\section{Submit your manuscript to a SpringerOpen ${ }^{\circ}$ journal and benefit from:}

- Convenient online submission

- Rigorous peer review

- Open access: articles freely available online

High visibility within the field

- Retaining the copyright to your article

Submit your next manuscript at $>$ springeropen.com 